\title{
BALANCING OF PULVERIZED COAL FLOWS TO BURNERS IN BOILERS WITH PRESSURIZED VERTICAL SPINDLE MILLS
}

FINAL REPORT FOR THE PERIOD

October 1, 2003 to March 31, 2005

\author{
by \\ Harun Bilirgen \\ Report Issued June 2005 \\ DOE Award Number DE-FC26-03NT41867 \\ Energy Research Center \\ Lehigh University \\ 117 ATLSS Drive \\ Bethlehem, PA 18015
}




\section{DISCLAIMER}

"This report was prepared as an account of work sponsored by an agency of the United States Government. Neither the United States Government nor any agency thereof, nor any of their employees, makes any warranty, express or implied, or assumes any legal liability or responsibility for the accuracy, completeness, or usefulness of any information, apparatus, product, or process disclosed, or represents that its use would not infringe privately owned rights. Reference herein to any specific commercial product, process, or service by trade name, trademark, manufacturer, or otherwise does not necessarily constitute or imply its endorsement, recommendation, or favoring by the United States Government or any agency thereof. The views and opinions of authors expressed herein do not necessarily state or reflect those of the United States Government or any agency thereof." 


\begin{abstract}
Numerical modeling of a vertical spindle mill was performed using commercially available CFD software, Fluent 6.1. The results of an experimental study that had been carried out for a Stairmand cyclone were used for model development and verification since both the vertical spindle pulverizer and the cyclone have strong swirling flow and particle separation within the geometry.
\end{abstract}

After the model verification study, numerical simulations were performed for a commonly used vertical spindle pulverizer. To understand the flow structures within the pulverizer, our study focused on the reference flow geometry, where there was no modification to the pulverizer. Examining the CFD model results guided us in designing flow control elements and positioning them in the discharge turret.

Numerical simulations were carried out with a spherical object positioned in the annulus region at the inlet of the discharge turret. The CFD results indicate that a spherical object positioned at the inlet plane of the discharge turret could effectively control the coal flow while having negligible effect on the primary air flow. Other flow controller designs will now be elevated in an effort to optimize the flow controller design and performance. 
TABLE OF CONTENTS

Page

$\begin{array}{lr}\text { INTRODUCTION } & 1\end{array}$

$\begin{array}{lr}\text { EXECUTIVE SUMMARY } & 4\end{array}$

NUMERICAL MODEL $\quad 5$

MODEL PULVERIZER AND UNIT DESCRIPTION 9

$\begin{array}{lr}\text { RESULTS AND DISCUSSIONS } & 10\end{array}$

DESIGNING FLOW CONTROL MECHANISMS 21

$\begin{array}{lr}\text { SUMMARY AND CONCLUSIONS } & 24\end{array}$

$\begin{array}{lr}\text { REFERENCES } & 26\end{array}$ 


\section{LIST OF FIGURES}

$\underline{\text { Figure }}$

Page

A Typical Vertical Spindle Pulverizer

2 Overview of the Segregated Solution Method

3 Computational Grid Layout

$4 \quad$ Full-Scale Vertical Spindle Pulverizer with Four Outlet Pipes

$5 \quad$ The Stairmand High-Efficiency Cyclone Used for Model Verification (units are in $\mathrm{mm}$ )

$6 \quad$ Cumulative Particle Size Distribution Used in Cyclone Study

$7 \quad$ Comparisons of Predicted Air Velocity Distribution with Experimental Data (Swirling Velocity Component)

$8 \quad$ Comparisons of Predicted Air Velocity Distribution with

Experimental Data (Axial Velocity Component)

$9 \quad$ Comparisons of Predicted Stairmand Cyclone Efficiency with Experimental Data

10 Particle Size Distribution Used in the CFD Model

11 Coal Flow Concentration Distribution within the Model Pulverizer (Reference Case)

13 Particle Concentration Distribution within the Model Pulverizer (Reference Case)

14 Particle Concentration Distribution Over the Outlet Pipe Cross-Sections at 135" Elevation (Reference Case)

15 Particle Concentration Distribution in the Discharge Turret at 110" Elevation (Reference Case) 100" Elevation (Reference Case) 


\section{LIST OF FIGURES (continued)}

Figure

Page

17 Particle Concentration Velocity Distribution in the Discharge Turret at 84" Elevation (Reference Case)

18 Spherical Object Located at the Inlet Plane of the Discharge Turret

19 Particle Concentration Distribution in the Discharge Turret with a Spherical Object Inserted In

20 Primary Air Velocity Distribution in the Discharge Turret with a Spherical Object Inserted In

21 Pulverizer Model to be Tested in Laboratory 


\section{LIST OF TABLES}

$\underline{\text { Table }}$

$\underline{\text { Page }}$

1 Particle Size Distribution of Conveyed Material (Coal) 


\section{INTRODUCTION}

Poor coal flow distribution to the burners is a common problem in pulverized coal (pc) boilers and has been considered as a potential area that needs to be addressed for improving unit performance, emissions, operations, and maintenance. With the introduction of new generation ultra low- $\mathrm{NO}_{x}$ burners, uniform distribution of coal flow to the burners has become an important issue due to restricted secondary air flow during the early stages of combustion. Coal pipe imbalances among the burners results in deviation from the design values for air-to-fuel ratios in the burners. This causes an associated deterioration in combustion efficiency due to increased carbon in fly ash level and leads to increased fuel and ash handling cost and possible deterioration in ESP collection efficiency.

In a typical vertical spindle pulverizer (Figure 1), raw coal is fed through a central coal pipe at the top of the pulverizer and falls by gravity to the rotating grinding table, mixing with classifier rejects returned for re-grinding. Centrifugal acceleration forces the coal outward to the grinding ring where it is pulverized between the ring and three grinding rollers. A nozzle ring on the outside perimeter of the grinding ring feeds primary air to the pulverizer. A stream of low-velocity air carries the particles of pulverized coal upward where they enter the classifier inlet vanes. Fine particles travel to the burners in the primary air stream, but the larger, heavier particles are returned to the grinding zone for further size reduction.

The flow distribution between the coal pipes is achieved as the mixture leaves from the pulverizer through a number of outlet pipes, each of which carries the flow into one individual burner. The number of outlet pipes on a typical vertical spindle mill varies between 2 and 8 . The distribution of primary air throughout the piping network is controlled by flow resistances of the various coal pipes. Because of differences in pipe lengths and numbers and types of elbows in each burner line, different coal pipes from a pulverizer will usually have different flow resistances. Orifices or flow restrictors 


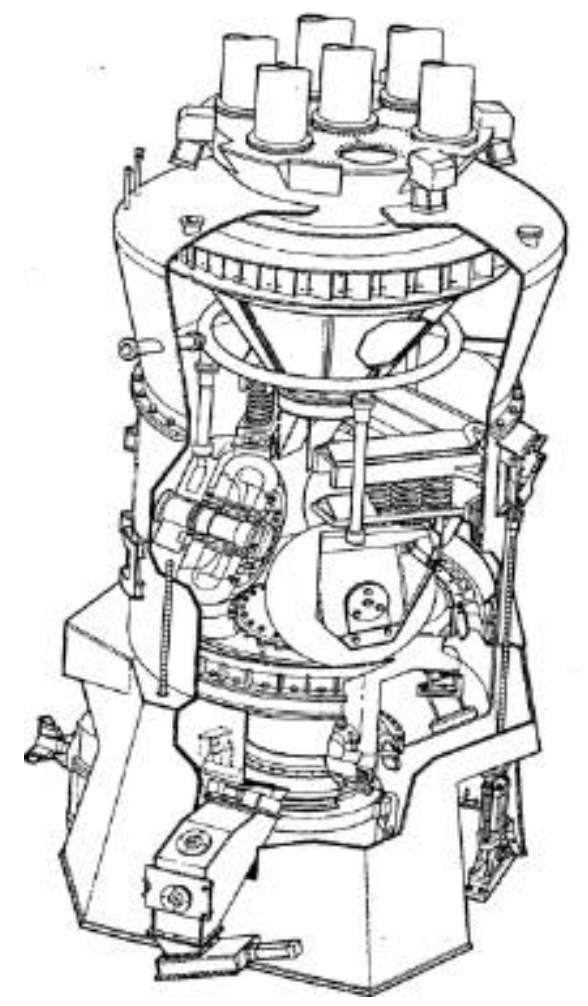

Figure 1: A Typical Vertical Spindle Pulverizer

installed within the pipes are used to adjust the individual primary air flows. While the use of orifices in the coal pipes can be an effective way of balancing air flow rates, evidence from field measurements suggests the orifices have little effect on distribution of coal flows between the coal pipes [1]. Instead, the coal flow distribution among the outlet pipes is strongly influenced by stratifications in the coal flow upstream of the outlet pipes, resulting fom mechanical problems within the pulverizer and flow nonuniformities at the inlet to the pulverizer.

The issue of poor coal distribution is a common problem in vertical spindle mills, adversely effecting unit performance and efficiency. Any deviation from the specified air-to-fuel ratio in a coal pipe results in a fuel rich or fuel lean zone in the vicinity of a particular burner. In particular, $\mathrm{CO}$ emissions and unburned carbon in fly ash particles are very sensitive to pipe-to-pipe coal flow imbalances. In addition, coal particle layout in long horizontal pipes can occur when a coal pipe carries more coal flow (fuel rich) 
than the design value. As particles accumulate in a horizontal pipeline, the primary air velocity locally increases due to the reduction in pipe cross-section area until it reaches a point at which high air velocity suddenly breaks the integrity of the particle structure accumulated in the horizontal pipeline, resulting in fuel rich combustion at the particular burner. This phenomenon periodically occurs when air-to-fuel ratio in any coal pipe is lower than the design value and it can lead to unstable flames. Field experience has shown that one or two individual burners having coal layouts can be responsible for increasing overall stack $\mathrm{CO}$ emissions and causing periodic $\mathrm{CO}$ spikes [2].

This study focused on developing an on-line coal flow control technology for vertical spindle pulverizers in pc boilers. Numerical computations were performed using commercially available Computational Fluid Dynamics (CFD) software. The CFD model was used to understand the complex three-dimensional flow structures in the upper half of the pulverizer and helped in designing flow control mechanisms. The design criteria for the proposed coal flow control mechanism are as follows:

- Negligible effect on primary air (PA) flow: The proposed design(s) must have negligible effect on the primary air (PA) flow distribution among burners because it is extremely difficult to control both coal and PA flows at the same time. In addition, controlling both coal and PA flows at the same time has a risk of lowering PA flow below the minimum conveying velocity in the pipelines, which can result in plugging the coal pipes.

- Low-pressure drop: Most power plants are fan limited and may not have extra room for additional pressure drop contributed by the proposed design. For this reason, the proposed coal flow control design(s) should have very small pressure drop.

- Easy to retrofit to existing pulverizers: The proposed design should be able to be retrofit to existing pulverizers with minor modifications. 


\section{EXECUTIVE SUMMARY}

This study focused on developing an on-line coal flow control technology for vertical spindle pulverizers commonly used with pulverized coal boilers. Numerical computations were performed using commercially available Computational Fluid Dynamics (CFD) software, Fluent. The CFD model was used to understand the complex three-dimensional flow structures in the upper half of the pulverizer and helped in designing the flow control mechanism.

The main objective of this study was to understand the flow structures within the pulverizer and develop an externally adjustable coal flow control mechanism design that can be used to control coal flow distribution among the outlet pipes. One of the most important design criteria is to have a flow control mechanism that has an effect on particle flow, but does not disturb the primary air flow distribution between the outlet pipes. This feature would greatly simplify the coal and primary air flow balancing process. The proposed apparatus should be readily installed within an existing vertical spindle pulverizer without causing a significant pressure drop. Since the flow control elements that are placed in the actual pulverizer are proposed to be coated against erosion by using tungsten carbide material, erosion of the flow control elements is not a concern.

As a part of computational model development of the full-scale vertical spindle pulverizer, experimental results which had been obtained for a Stairmand cyclone were used to validate the numerical model. The experimental data also helped to determine the CFD model parameters.

After model development and its verification, a full-scale pulverizer was modeled for the reference case, where there was no modification to the pulverizer. Examining the flow structures within the pulverizer guided us in designing the flow control elements and positioning them in the discharge turret.

A spherical object located at the inlet plane of the discharge turret was modeled as a flow control element. It was found to be effective in controlling coal flow going through the outlet pipes while having negligible effect on the PA flow. Other flow controller designs will now be evaluated in an effort to optimize the flow controller design and performance. 


\section{NUMERICAL MODEL}

Numerical simulations were performed with commercially available CFD software, FLUENT 6.1. The solution method is based on the fundamental governing equations of fluid dynamics - the continuity and momentum equations. The flow is assumed to be at steady-state conditions.

The numerical analysis is based on the solution of the Reynolds Averaged Navier-Stokes (RANS) equations. The main numerical features of the software are as follows:

- Finite volume method with multi-block grid and adaptive time step.

- Body fitted coordinate system with the Rhie-Chow algorithm, which allows the treatment of arbitrary two- and three dimensional complex geometries.

- Several equation solvers including an Algebraic Multigrid Method (AMG) and a variety of differencing schemes.

- Pressure-velocity coupling using the SIMPLE, SIMPLEC or PISO algorithms.

- Various turbulence models including the standard model, the low Reynolds number model, the RNG model, the Reynolds stress model, and the Reynolds flux model.

The numerical calculations for the gas phase were performed by solving a set of Reynolds averaged Navier-Stokes equations together with Reynolds Stress turbulence model. The general form of the elliptic differential equations can be found in Ref 4 .

The gas phase turbulence quantities were predicted using the Reynolds Stress model, together with the isotropic eddy viscosity hypothesis which relates the Reynolds stress linearly to the mean velocity gradient. Instead of modeling the term, one adopts the generalized Boussinesq eddy viscosity model. In the vicinity of wall, the turbulence becomes more complex because of the no-slip condition at the wall where flow is reduced to laminar flow and the molecular viscosity dominates. Also, in the near wall 
zone, the velocity and other transport properties vary rapidly within a short distance from the wall. In order to predict the rapid variation in this region, very good grid resolution is required which increases the computational time.

The particulate phase was treated by the Lagrangian approach. In this model, the particles are grouped in so called "parcels", a collection of particles with the same properties. The parcels are introduced at a finite number of starting locations at the inlet cross-section and move simultaneously through the flow field. In every given time step, their positions and velocities are calculated according to the forces acting on the particle and using Newton's second law.

The interactions between these eddies and the particles are taken into account by a stochastic procedure, referred to as the eddy life time concept. It is assumed that the turbulence is isotropic and that the instantaneous fluid velocity component is sampled from a Gaussian velocity distribution. The instantaneous fluid velocity is assumed to influence the particle motion during the lifetime of an eddy. During this period the particles interact with a sequence of randomly directed eddies.

Particle-wall collisions were modeled using a coefficient of restitution, having a value of 0.9 in all the calculations. The coefficient of restitution is defined as the ratio of the normal velocity component after impact to that before impact. In order to provide data to numerical models, a number of studies have been performed to investigate the collision characteristics of solid particles with a wall. Particle-particle collisions were neglected in this study. This is a good assumption for dilute gas-particle flows. However, as the particle concentration becomes higher, particles collide with each other and the loss of particle kinetic energy cannot be neglected.

At the exit of the pulverizer outlet pipes, atmospheric pressure was specified as a boundary condition. No-slip boundary conditions at the wall and the wall function concept were used for the near wall regions of the flow, eliminating the necessity of extremely fine grids in these regions. 
A total of 500,000 computational particles was tracked throughout the flow domain. Each computational particle (or parcel) carried the same flow rate and was assumed to be spherical. The particle diameters were stochastically sampled using the Rossin Rammler distribution function (Equation 1) and particle size distribution information obtained from sieve analysis given in Table 1.

$$
\operatorname{Pr} \text { ob }(\text { Diameter }>d)=\exp \left[-\left(\frac{d}{d_{m}}\right)\right]^{n}
$$

Table 1

\section{Particle Size Distribution of Conveyed Material (Coal)}

\begin{tabular}{|c|c|}
\hline $\begin{array}{c}\text { Diameter } \\
(\mathrm{mm})\end{array}$ & $\begin{array}{c}\text { Cumulative } \\
\text { Weight (\%) }\end{array}$ \\
\hline$>150$ & 1.205 \\
\hline $106-150$ & 3.916 \\
\hline $90-106$ & 6.32 \\
\hline $75-90$ & 10.04 \\
\hline $53-75$ & 19.3 \\
\hline $38-53$ & 32.43 \\
\hline$<25$ & 97.79 \\
\hline
\end{tabular}

Partial differential equations [3] were discretized by using the finite volume discretization technique and the unstructured grid features of the pre-processor software (GAMBIT). The purpose of the discretization process is to divide the entire computational domain into small discrete control volumes. The governing equations are, therefore, numerically integrated over each individual control volume to construct algebraic equations for the discrete dependent variables such as velocities, pressure, and temperature. Algebraic equations were first linearized implicitly and then solved using the segregated solution algorithm as illustrated in Figure 2 This results in a system of linear equations with one equation for each cell in the domain. A linear equation solver was used in conjunction with an algebraic multigrid (AMG) method to solve the resultant system of equations for the dependent variable in each cell. The segregated solution approach solves for a single variable field by considering all cells at the same time. It then solves for the next variable field by again considering all cells at 
the same time. Solution of the system of equations continues until a converged solution is obtained. Converged solutions were assumed to be obtained when the normalized residuals, the time rate change of the conserved variable, decreased to their minimums and remained unchanged as iterations continued. A converged solution was obtained in approximately 1 month for a typical run with using Lehigh University's Computing Center computers (Silicon Graphics - SGI Origin 3800 super computer).

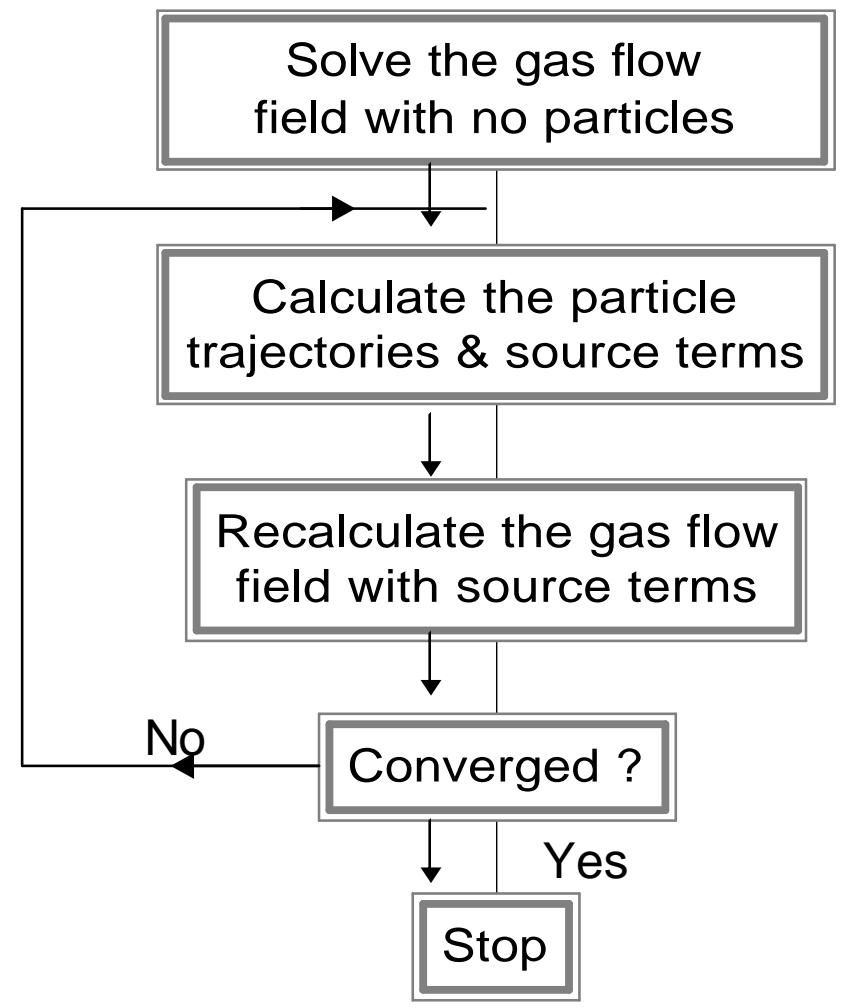

Figure 2: Overview of the Segregated Solution Method

Figure 3 shows the computational model used in this study. The left panel of the figure shows the CFD model with the internal geometrical details while the right panel shows computational grids. 


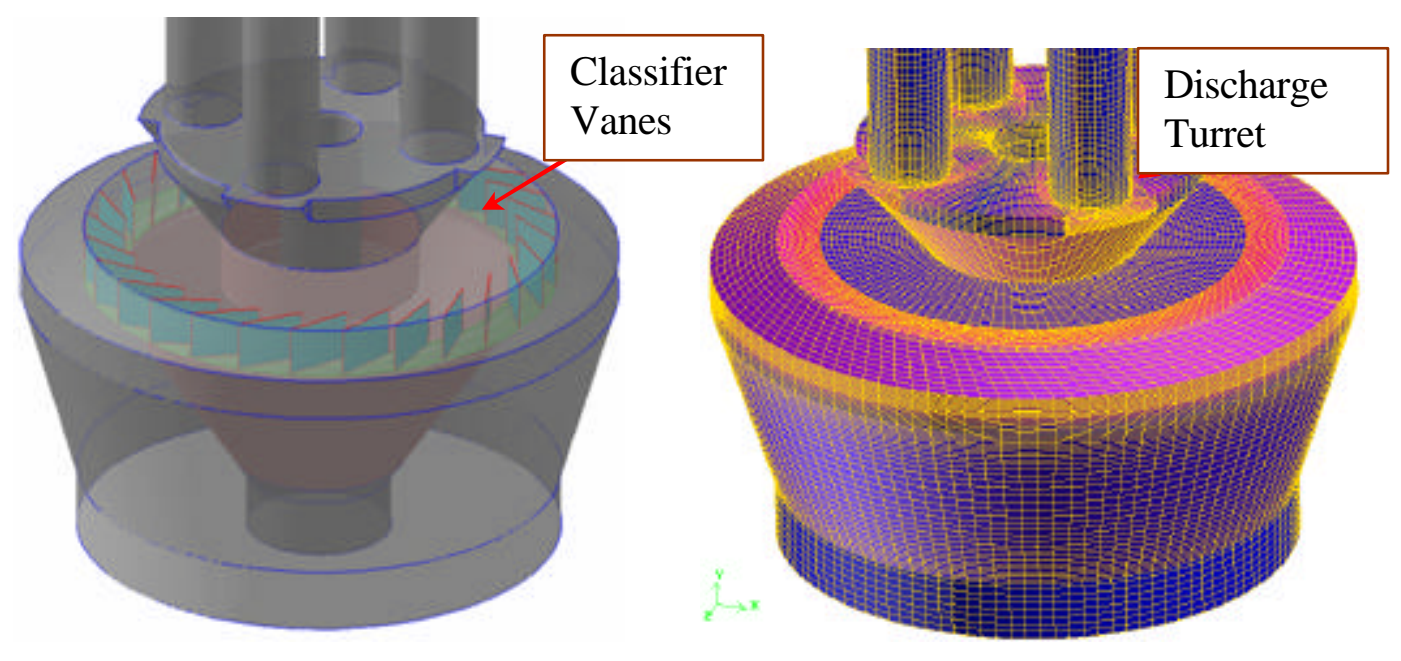

Figure 3: Computational Grid Layout

\section{MODEL PULVERIZER AND UNIT DESCRIPTION}

Based on information gathered from industry, a commonly used pulverizer configuration was picked. The selected pulverizer is a four outlet Babcock and Wilcox (B\&W) MPS 89 vertical spindle pulverizer and is being used in a $600 \mathrm{MW}$ wall-fired boiler. The boiler utilizes six B\&W MPS 89 vertical spindle mills, each of which has four 24-inch ID outlet pipes (Figure 4). A one-day field trip was arranged to the station to collect pulverizer operational data and geometrical information. Coal samples were extracted from three coal pipes and from the pulverizer just upstream of classifiers by using an extraction probe. A detailed technical drawing of the pulverizer was provided by the equipment company $(\mathrm{B} \& \mathrm{~W})$. Operational issues of the pulverizer were discussed with the unit engineers and boiler operators.

The boiler is a supercritical opposed wall-fired Foster Wheeler design with a nominal output of $650 \mathrm{Mw}_{\mathrm{g}}$. The unit has a double reheat with a maximum continuous rating (MCR) of 4,000,000 lb/hr. There are 24 burners arranged in three elevations per wall with four burners per elevation. 
Outlet Pipes

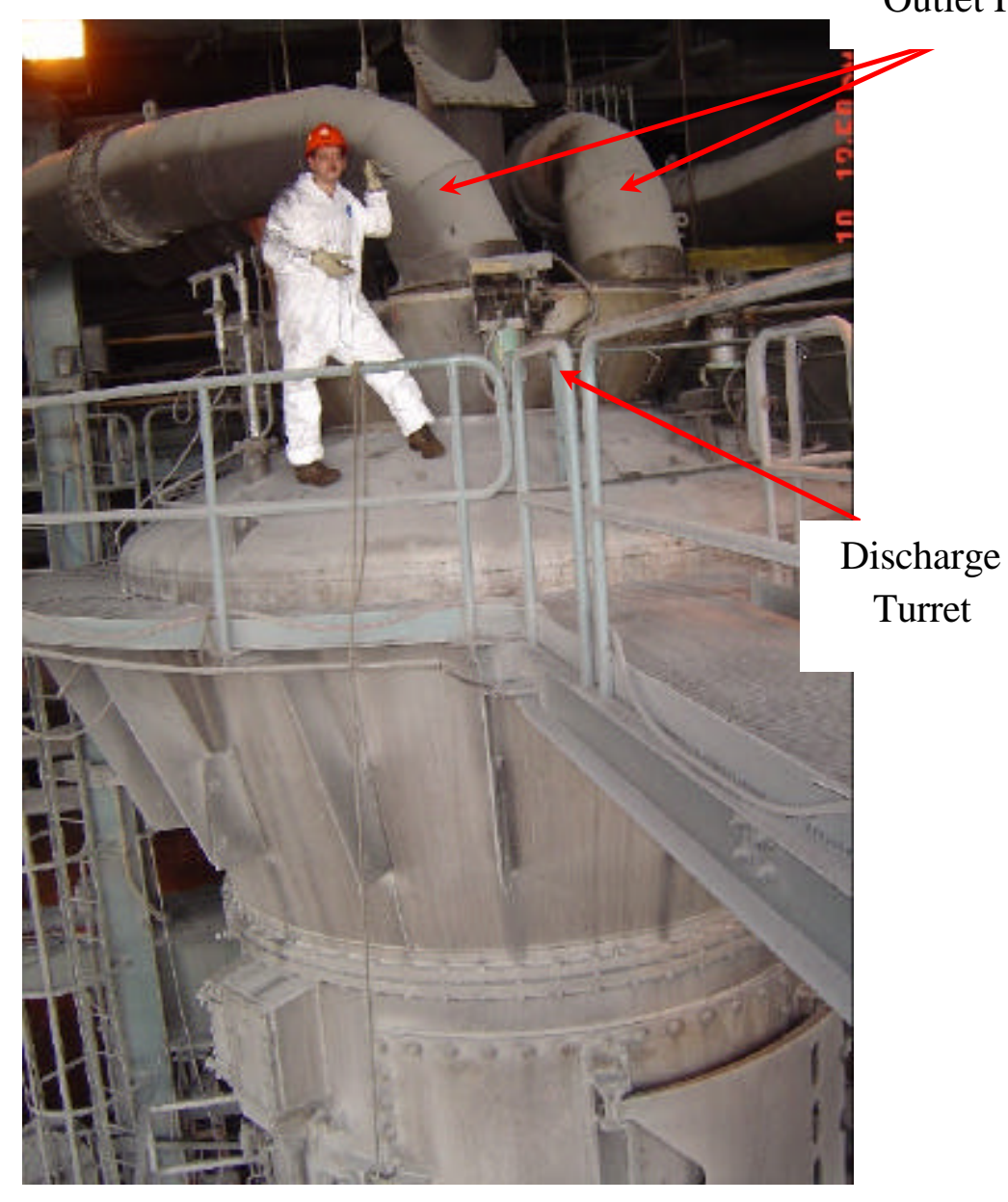

Figure 4: Full-Scale Vertical Spindle Pulverizer with Four Outlet Pipes

\section{RESULTS AND DISCUSSIONS}

As a part of computational model development of the full-scale vertical spindle pulverizer, a literature review was carried out to find available experimental data for the geometries similar to the vertical spindle pulverizer. A Stairmand cyclone was found to be very similar to the vertical spindle pulverizer since both have strong swirling flow and particle separation within the geometry. The objective of the literature survey was to first find available experimental data for a geometry similar to the vertical spindle pulverizer and then verify the CFD model against experimental data. The experimental data also helped to determine the CFD model parameters. 
An experimental study that had been conducted for a Stairmand high-efficiency cyclone was taken into consideration for model verification [4]. In this study [4], measurements of the tangential and axial velocity components of gas flow were performed by Laser Doppler Anemometry (LDA). The cyclone pressure drop and overall collection efficiency were also measured as a function of the inlet velocity and the exit pipe diameter. Figure 5 illustrates the physical dimensions of the Stairmand cyclone used in experiments by Hoekstra [4] and in this study for the CFD model validation.

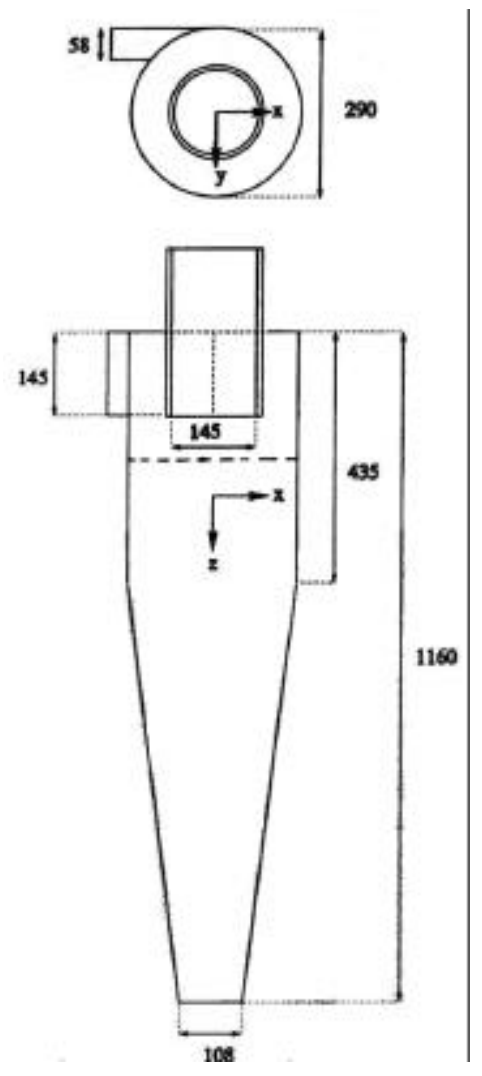

Figure 5: The Stairmand High-Efficiency Cyclone Used for Model Verification (units are in $\mathrm{mm}$ )

The inlet air velocity was varied from 10 to $30 \mathrm{~m} / \mathrm{s}$ while the cyclone was operated at a constant solids loading of $2.8 \times 10^{-3} \mathrm{~kg}$ solids $/ \mathrm{kg}$ gas. In the measurements, chalk dust with a density of $2,740 \mathrm{~kg} / \mathrm{m}^{3}$ was used. The particle size distribution of the dust is shown in Figure 6. 


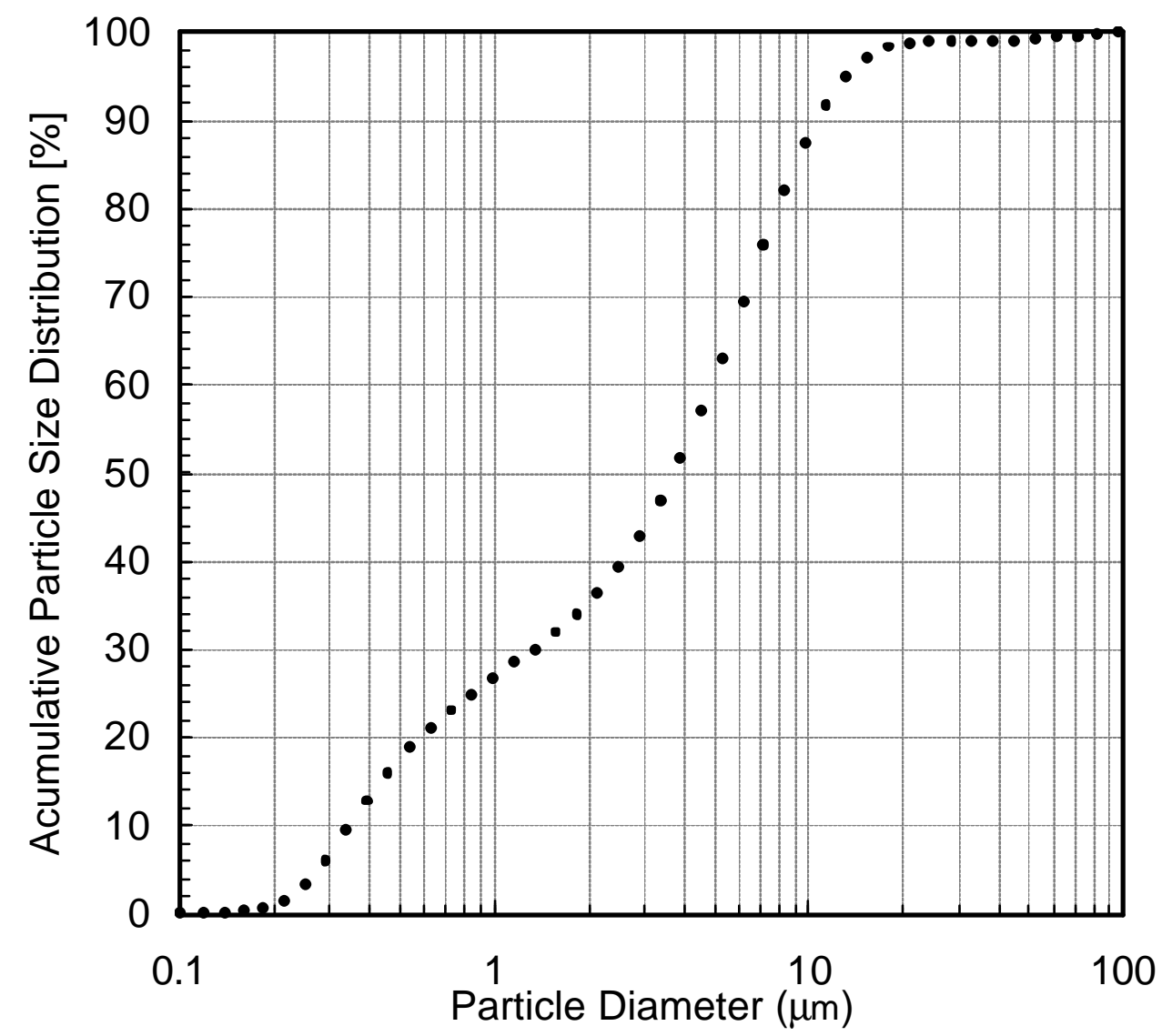

Figure 6: Cumulative Particle Size Distribution Used in Cyclone Study

In the verification study, our efforts focused on determining the most suitable numerical model parameters for strong swirling flows. A number of turbulence models were tested including the Reynolds stress transport model (RSTM), standard k- $\varepsilon$ model, and Renormalization group (RNG) model.

The comparisons between the experimental data and the CFD simulations for the swirling and the axial components of the air velocities are shown in Figures 7 and 8, respectively. For the tangential velocity component (Figure 7), all three turbulence models were in fairly good agreement with the experimental data. For the axial velocity component (Figure 8), however, only the RSTM is capable of predicting the characteristic radial distribution of the axial velocity component. 


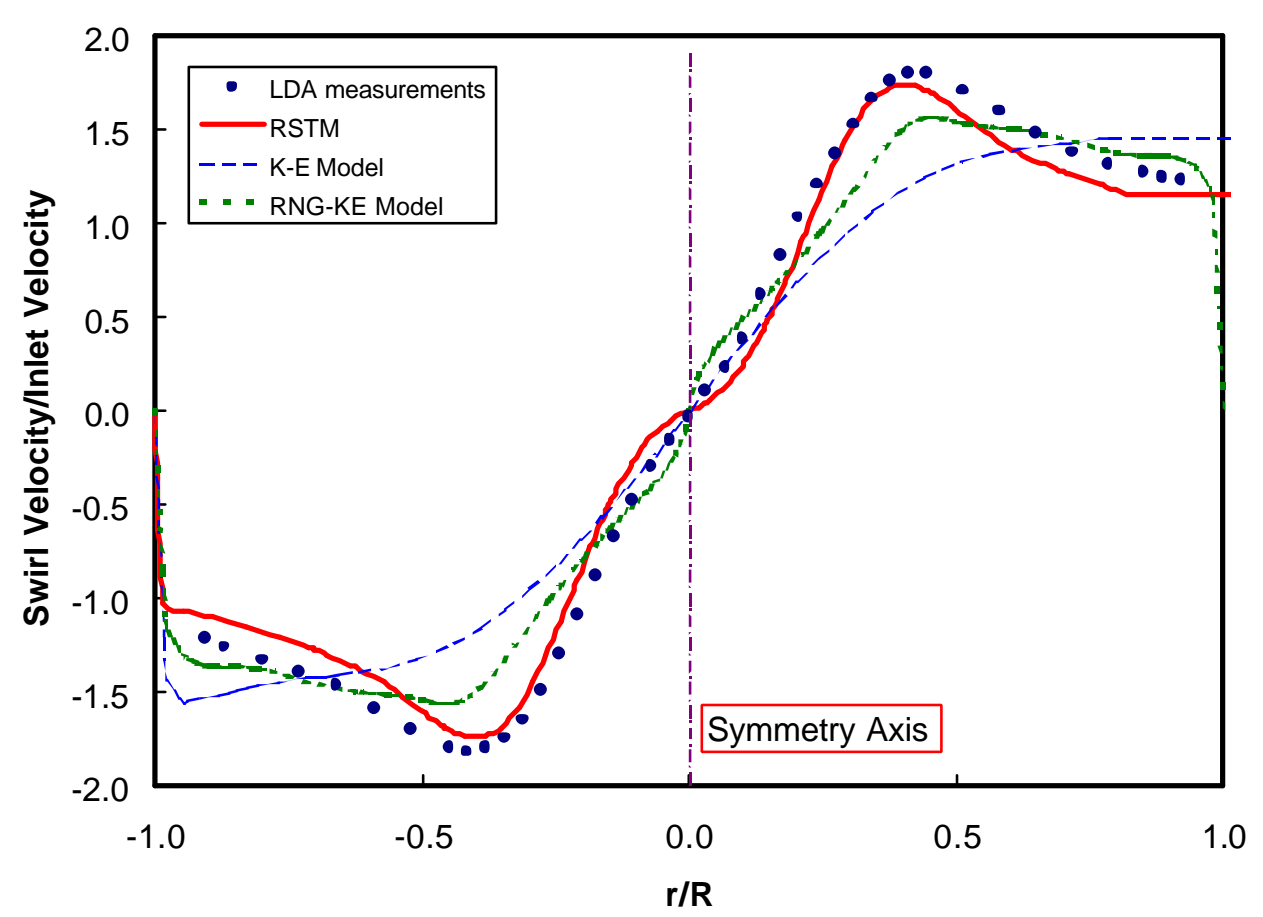

Figure 7: Comparisons of Predicted Air Velocity Distribution with Experimental Data (Swirling Velocity Component)

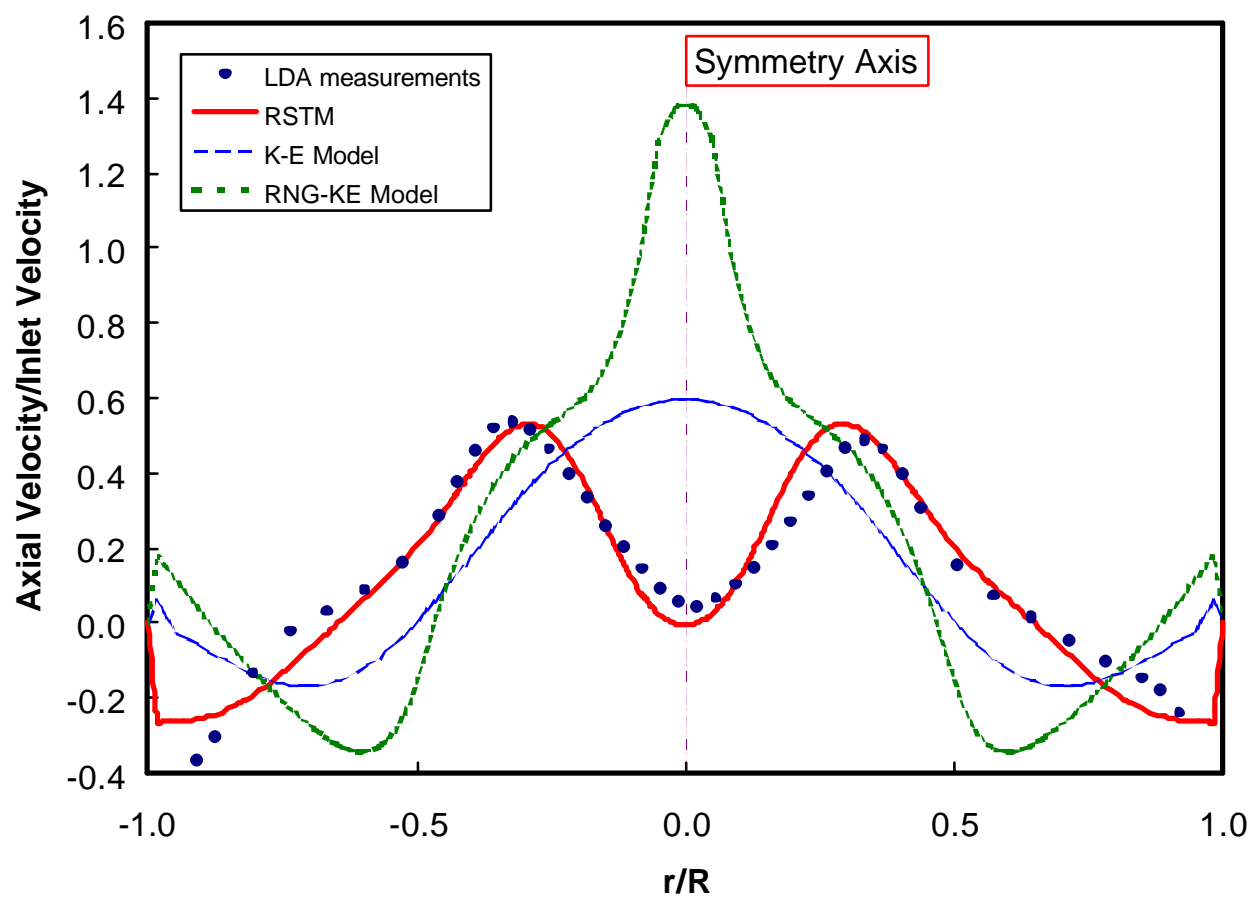

Figure 8: Comparisons of Predicted Air Velocity Distribution with Experimental Data (Axial Velocity Component) 
Based on the comparisons between the experimental data and the CFD model, the RSTM was found to be the most suitable turbulence model in predicting the flow domain in strong swirling flow as in the case of a cyclo ne.

Figure 9 shows the computed overall cyclone collection efficiency as a function of cyclone inlet velocity together with the experimental data obtained from Reference 4. As can be seen from this figure, the CFD results for the overall cyclone efficiency agree very well with the experimental data, concluding that the CFD model parameters are accurate enough to model strongly swirling flows.

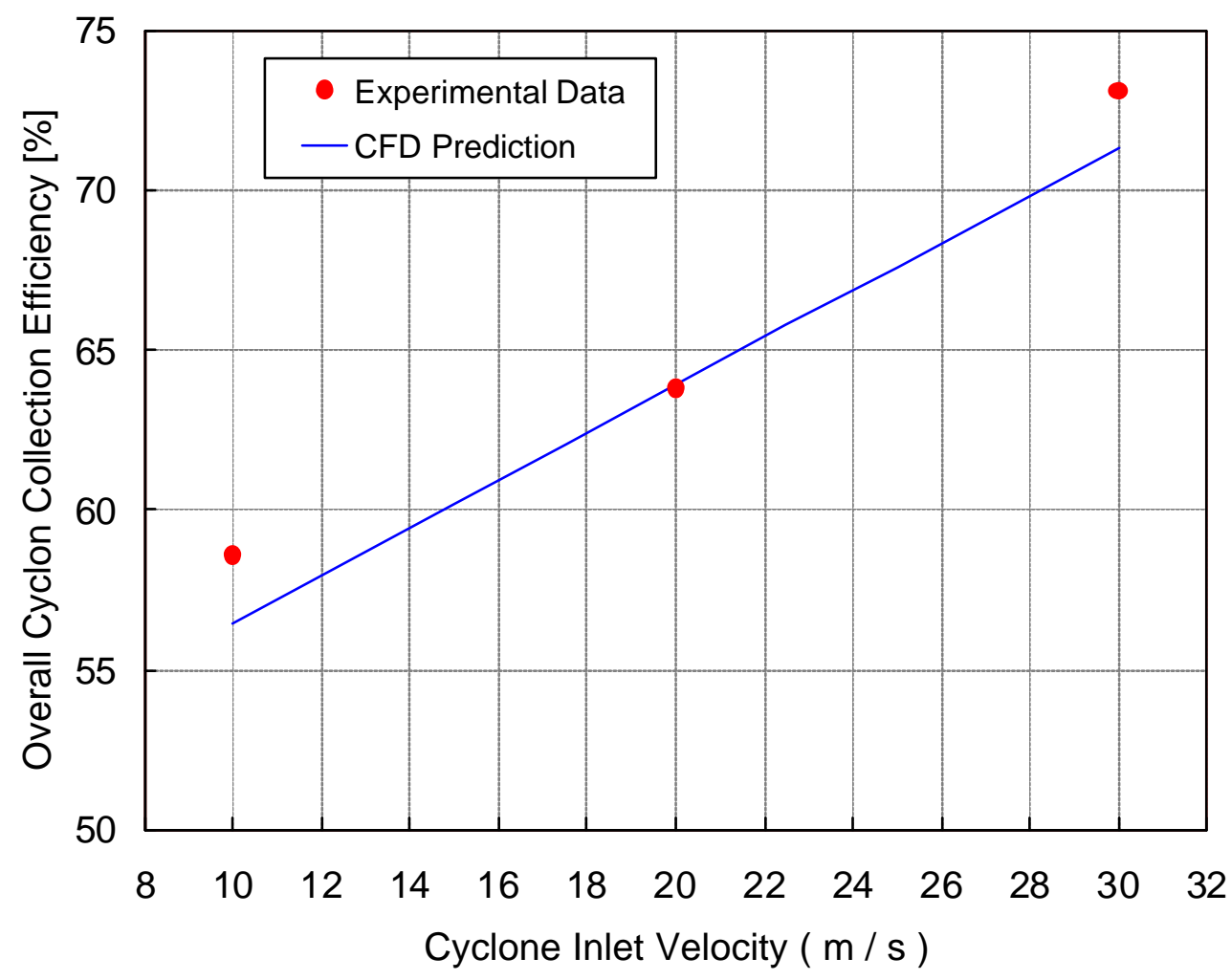

Figure 9: Comparisons of Predicted Stairmand Cyclone Efficiency with Experimental Data

After the CFD model development and verification against the experimental data, a CFD model was built for the full-scale vertical spindle pulverizer geometry. 
The particle size distribution was obtained by performing sieve analysis on the coal samples extracted from the pulverizer's outlet pipes. According to the sieve analysis results and Rossin Rammler particle distribution function, the particles have a mean diameter of $34.5 \mu \mathrm{m}$ and a spread of the data from the mean of 1.05. A uniform particle concentration and velocity distribution was defined at the inlet of the computational flow domain. Similarly, a uniform air flow velocity was set at the inlet of the geometry. Figure 10 illustrates the Rossin Rammler particle size distribution function for the coal samples used in the CFD model.

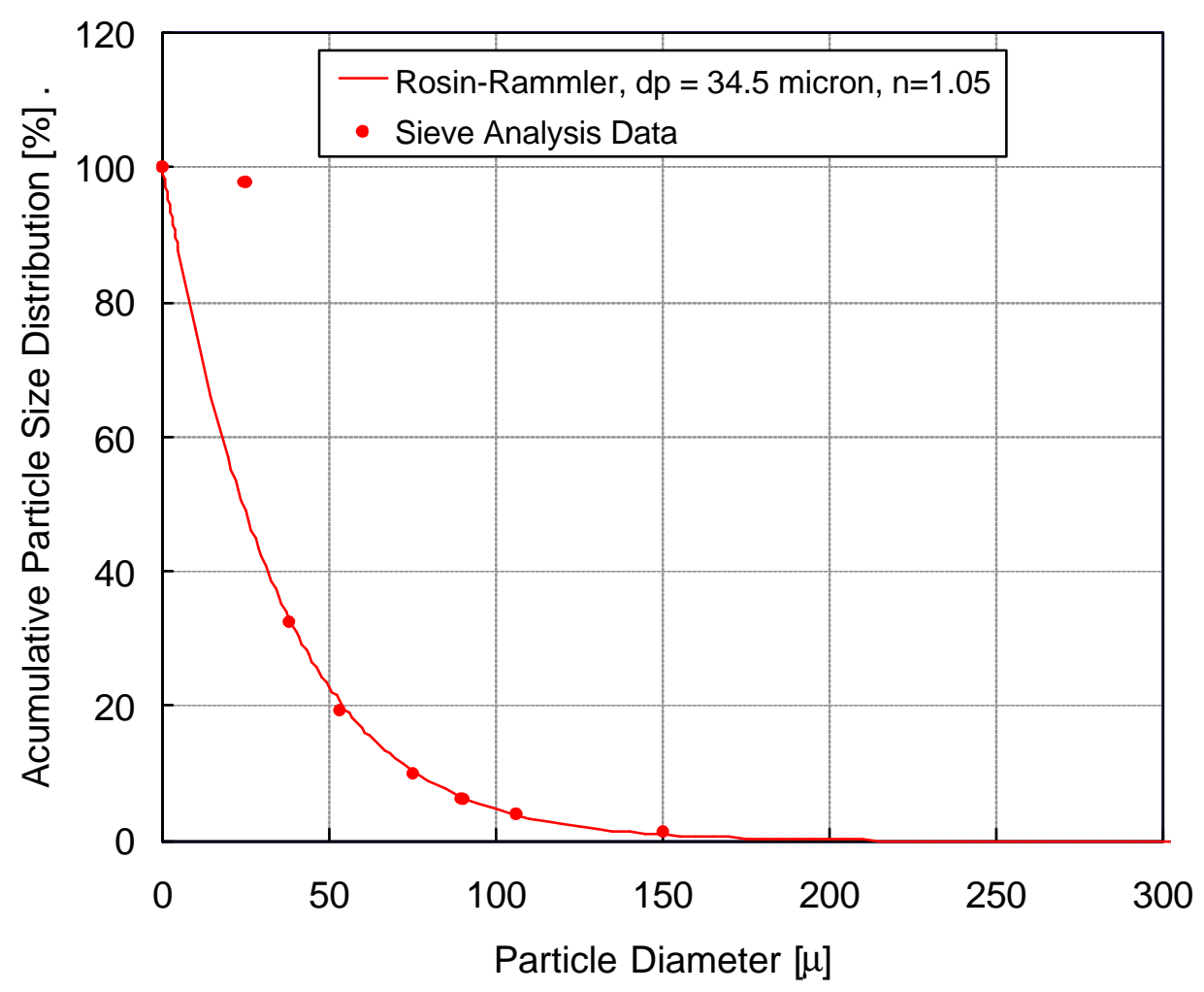

Figure 10: Particle Size Distribution Used in the CFD Model

The CFD simulations were first performed for the reference flow geometry, where there was no modification to the pulverizer. The objective was to understand the $\infty a l$ and air flow structures in the upper region of the pulverizer. A typical CFD run for the reference geometry took approximately one month of computational time to reach a fully converged solution. 
The CFD simulation results for the reference case indicated that equal air and coal flows between the outlet pipes were achieved for the case where a uniform coal and particle flow distribution existed at the inlet plane of a perfectly symmetrical vertical spindle pulverizer. For the CFD model, these results are very reasonable since there are no geometrical imperfections or stratifications in both air and coal flow structures that prevent the uniform distribution of coal and air flows among the outlet pipes. However, in an actual pulverizer, it is almost impossible to establish a uniform coal and air flow distribution within the pulverizer due primarily to maintenance and adjustment issues of the internal parts of the pulverizer. In addition, in most vertical spindle pulverizer designs, the primary air flow is non-symmetrically fed at the bottom of the mills. Although a distributor plate (located immediately upstream of the grinding table) is used to make the air flow distribution uniform at the pulverizer inlet, it does not eliminate stratifications in the primary air flow and subsequently in the coal flow distribution in the pulverizer.

Figure 11 depicts the coal flow concentration distribution within the pulverizer for the reference case. The coal and air mixture makes a number of turns before it reaches the inlet of the outlet pipes. The flow mixture first makes a U-turn in the z-axis plane as it gains tangential velocity while going through classifier vanes in the y-axis plane. The classifier vanes are set to 54 degrees (Figure 3). Immediately before the discharge turret inlet, the mixture makes another U-turn in the z-axis plane just before it enters the discharge turret. The changes in direction of the flow cause the majority of particles to accumulate in the outer region of the pulverizer. It is the centrifugal force (created by the second U-turn) that forces the heavier particles to fall down to the bottom of the pulverizer for more grinding. Immediately after particles enter the discharge turret, they are forced toward the outer wall by the tangential and radial velocity components of the air flow. In a very short axial distance in the discharge turret the majority of the particles accumulate in the vicinity of the discharge turret's outer wall. The drag force in the radial direction due to he flow expansion and the centrifugal force created by the tangential velocity within the discharge turret are the major parameters that determine 
the particle trajectories and consequently the particle flow distribution between the outlet pipes.
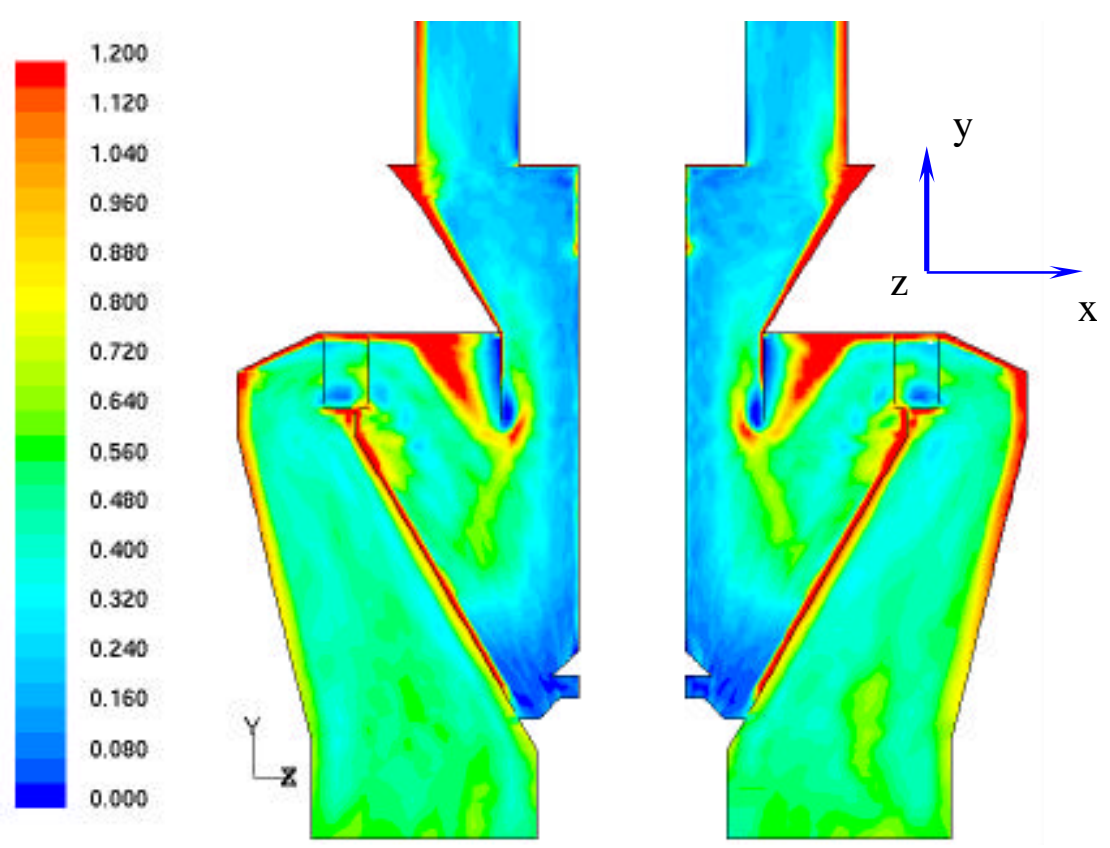

Figure 11: Coal Flow Concentration Distribution within the Model Pulverizer (Reference Case)

The CFD simulation results showed that the tangential velocity component of the particles within the discharge turret was approximately 45 degrees for a classifier angle position of 54 degrees.

It can clearly be seen from Figure 11 that a phase separation between air and coal flows occurs both within the pulverizer and in the discharge turret. The main reason for the phase separation is the density difference between the air and the particulate phase. The particulate phase density is approximately more than 1000 times higher than that of air.

Figure 12 illustrates the velocity vector field of the air flow. Similar to the coal flow, stratification in air flow is also observed as the air flow makes U-turns. However, the stratification in the air flow is not as severe as that in the coal flow. One of the most interesting differences in the flow structures between two phases can be observed at 
the inlet region of the discharge turret. Comparison of Figures 11 and 12 reveals that a high particle concentration region is formed in the outer wall of the inlet of the discharge turret where relatively low air velocities exist. The annulus region of the inlet of the discharge turret can simply be divided into two regions: the outer wall region with high particle concentration and low primary air flow rate and inner wall region with very low particle concentration and high primary air flow rate. Phase segregation within the discharge turret is initiated at the entrance of the discharge turret and propagates as the mixture advances in the axial direction.
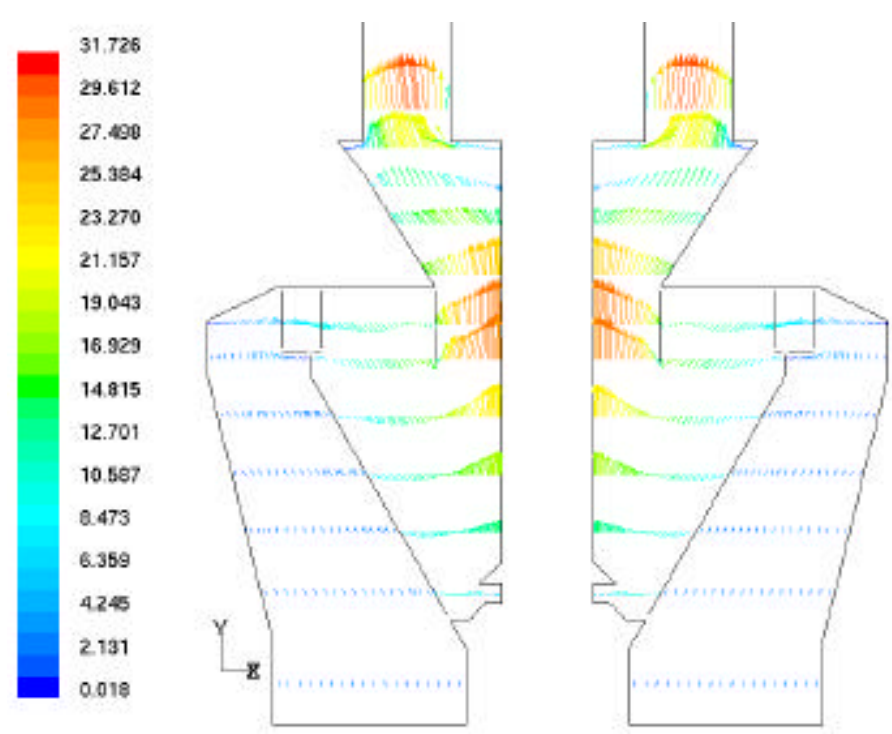

Figure 12: Air Velocity Vectors within the Model Pulverizer (Reference Case)

Figure 13 shows the particle concentration distribution in the z-axis plane together with the marked positions in the axial direction at which the particle concentration distributions are shown in detail in Figures 14 through 16. Figure 17a shows particle concentration distribution at $y=84$ " plane while Figure $17 \mathrm{~b}$ shows primary air velocity distribution at the same plane. 

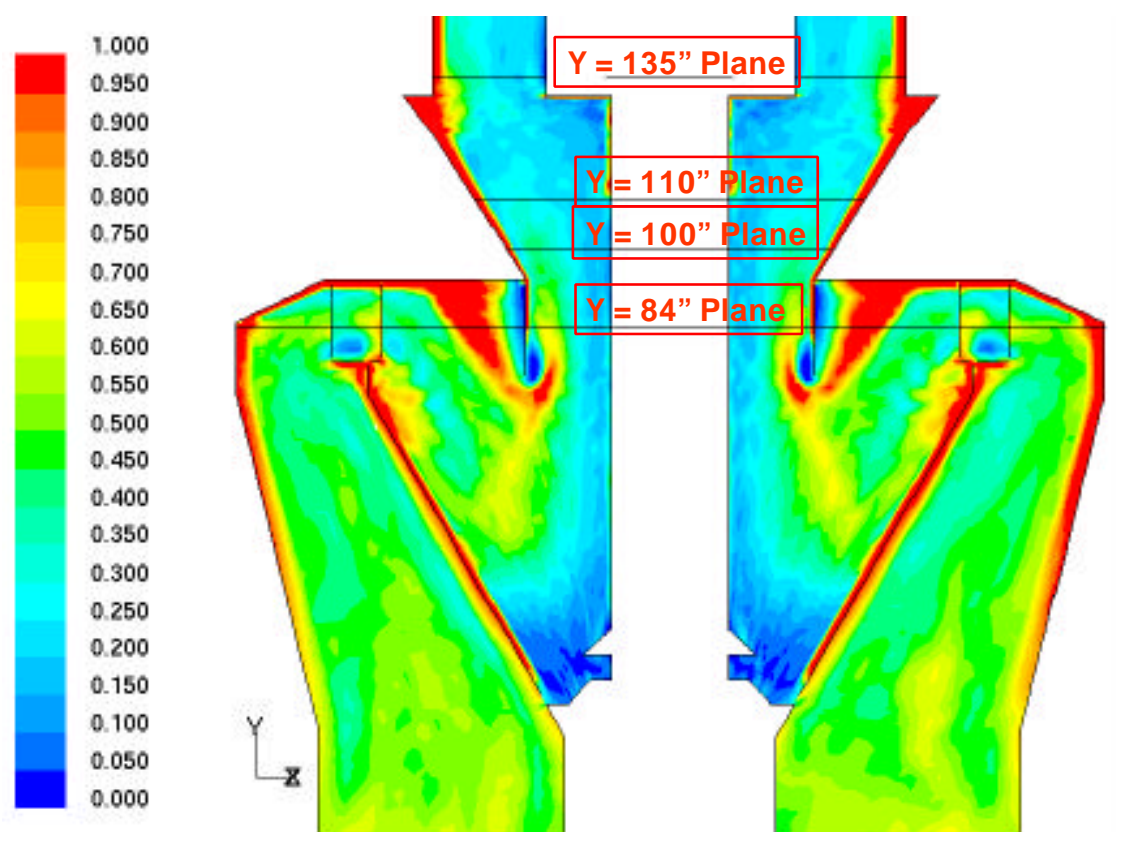

Figure 13: Particle Concentration Distribution within the Model Pulverizer (Reference Case)

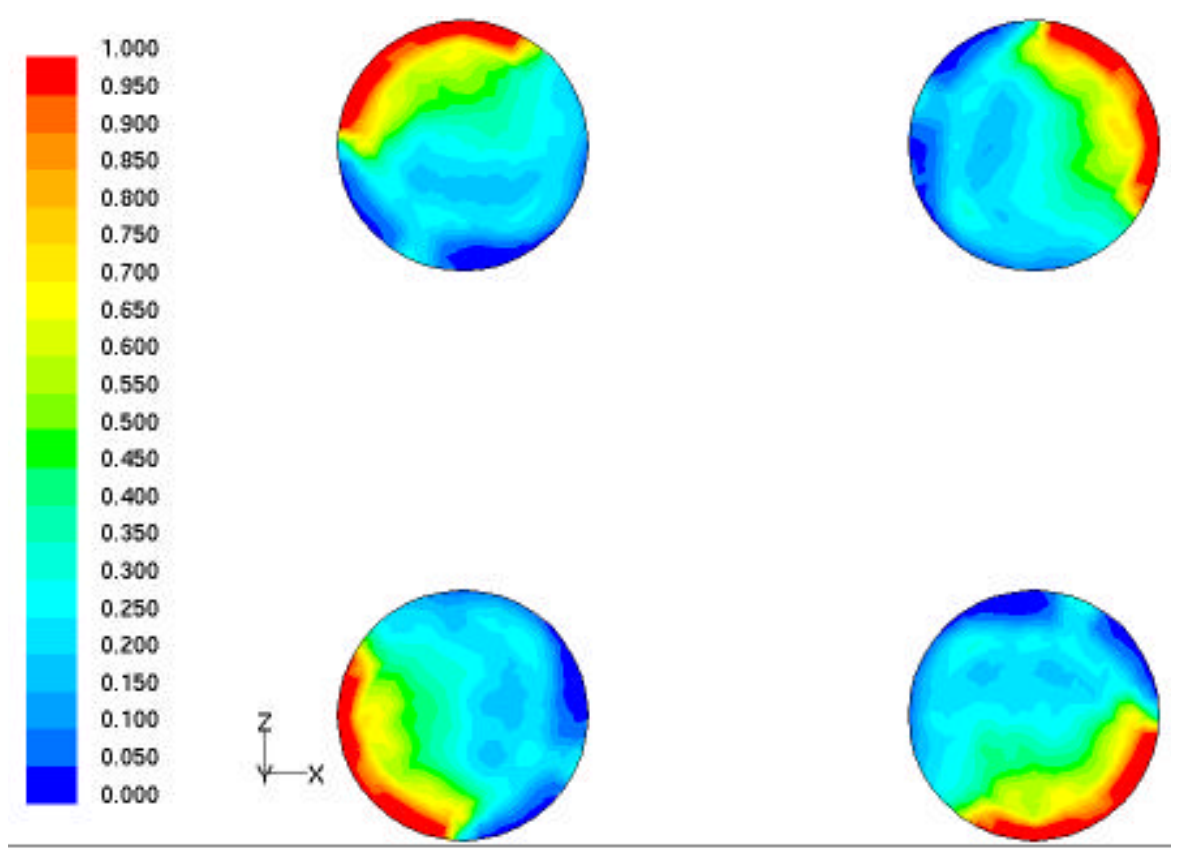

Figure 14: Particle Concentration Distribution Over the Outlet Pipe Cross-Sections at 135" Elevation (Reference Case) 


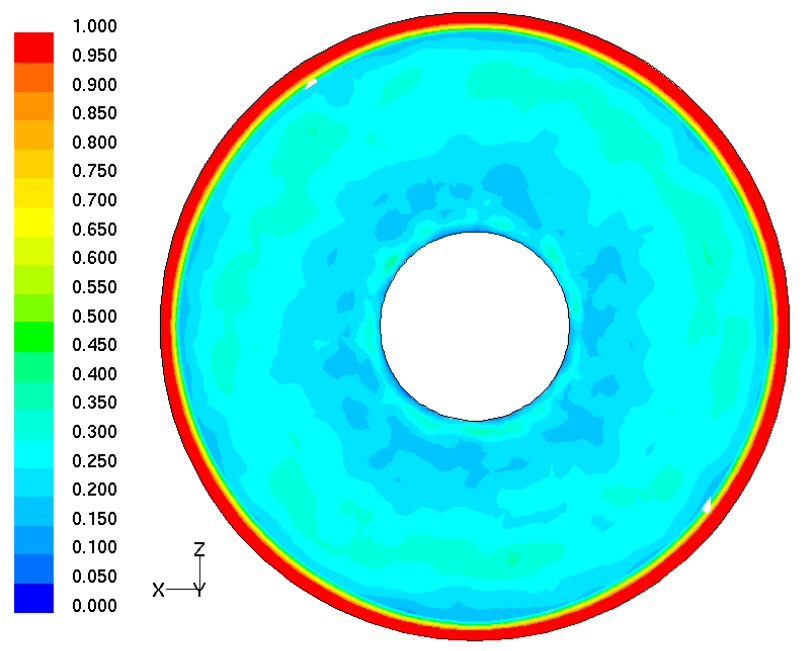

Figure 15: Particle Concentration Distribution in the Discharge Turret at 110" Elevation (Reference Case)

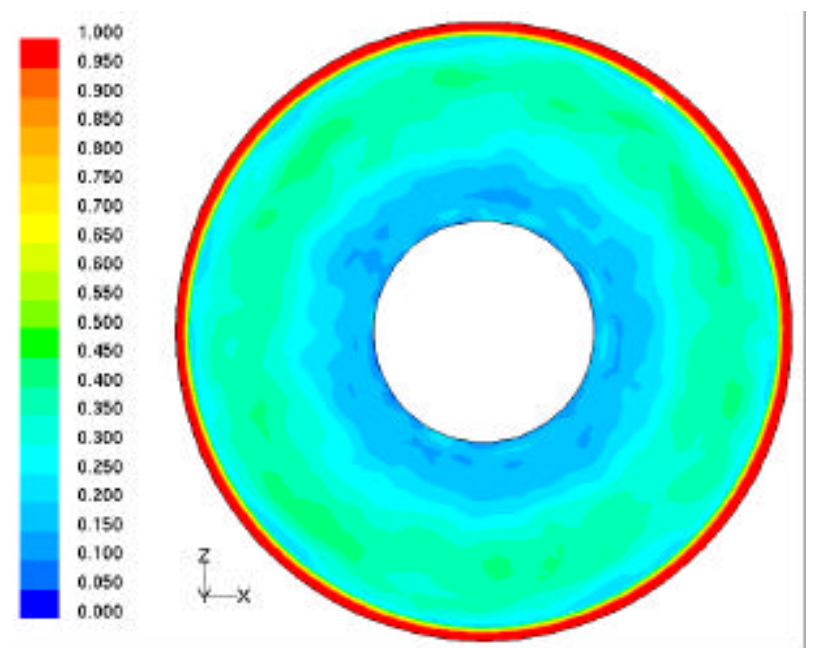

Figure 16: Particle Concentration Distribution in the Discharge Turret at 100" Elevation (Reference Case) 


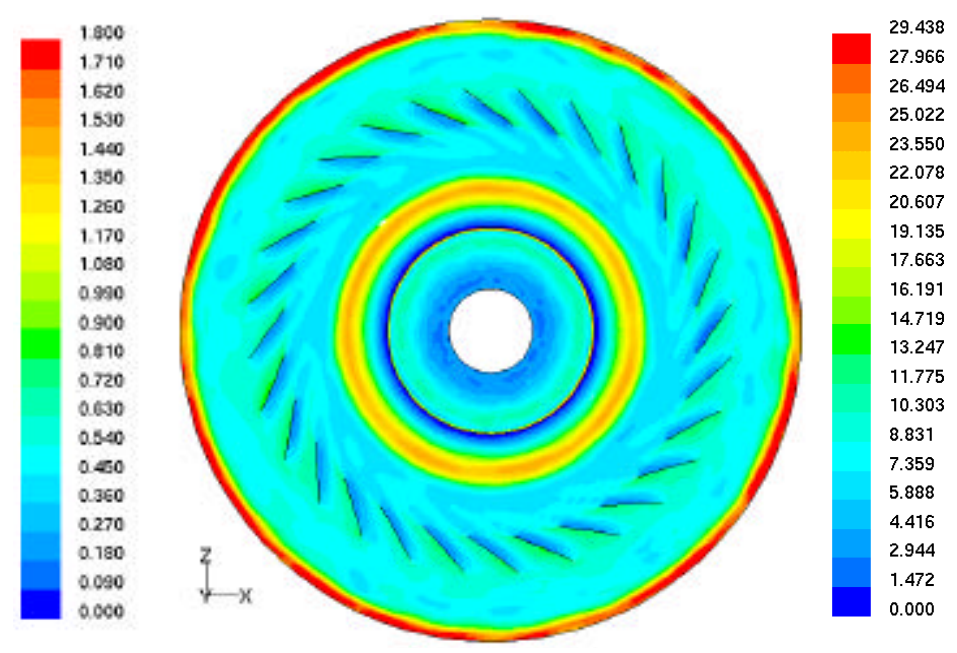

a) Particle Concentration $\left(\mathrm{kg} / \mathrm{m}^{3}\right)$

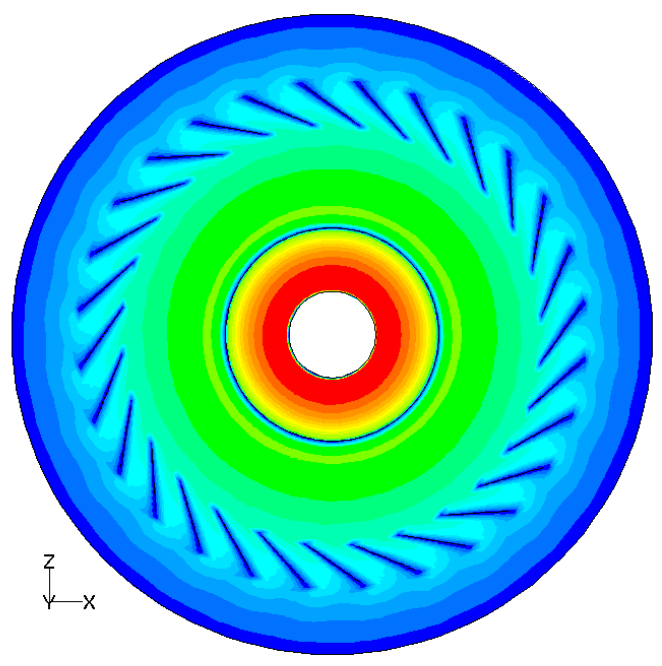

b) Air Velocity $(\mathrm{m} / \mathrm{s})$

Figure 17: Particle Concentration Velocity Distribution in the Discharge Turret at 84" Elevation (Reference Case)

\section{DESIGNING FLOW CONTROL MECHANISMS}

The main objective of this study is to understand the flow structures within the pulverizer and develop an externally adjustable coal flow control mechanism design that can be used to dynamically control coal flow distribution among the outlet pipes. One of the most important design criteria is to have a flow control mechanism that affects particle flow while not disturbing the primary air flow distribution between the outlet pipes. This feature greatly simplifies the coal and primary air flow balancing process. The proposed apparatus should be readily installed within an existing pressurized vertical spindle pulverizer without causing a significant pressure drop. Since the flow control elements that are placed in the actual pulverizer are proposed to be coated against erosion by using tungsten carbide material, erosion of the flow control elements is not a concern.

Figure 18 shows the proposed location and geometry of one of the candidate flow control element designs. It is a spherical object inserted in the annulus region of the discharge turret's entrance. The main idea for this design is to create a wake for particle flow upstream of the inlet of the outlet pipes, changing the particle paths within 
the discharge turret. The position and geometry of the flow control elements are two of the most important parameters that control the trajectories of the particles. Since the object is positioned far from the outlet pipe inlets, it is expected that it will have negligible impact on the air flow distribution.

The candidate flow control elements would be externally controlled with 90degrees rods attached to the spherical balls. The location of the flow control element is adjusted with respect to the inlet of the outlet pipes by rotating the rod in the x-axis plane, changing the location of the particle wake upstream of the outlet pipes. This will subsequently affect the distribution of the coal flow between the outlet pipes.

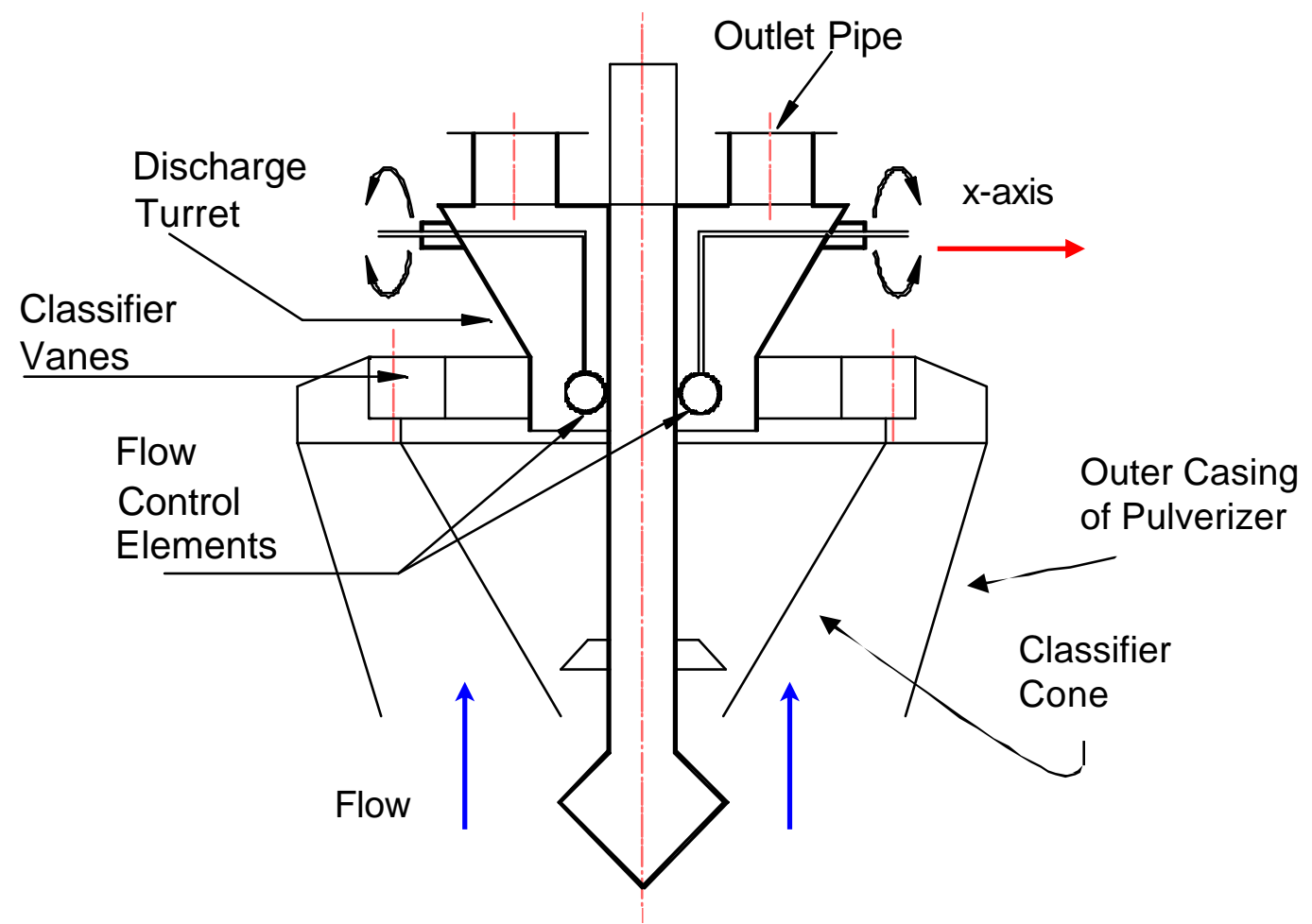

Figure 18: Spherical Object Located at the Inlet Plane of the Discharge Turret

Figure 19 shows the particle concentration distribution in the discharge turret with the spherical object inserted as shown in Figure 18. The CFD simulations were conducted only for a symmetrical flow condition in which only a quarter of the model geometry with one spherical object was modeled. The CFD results with the quarter geometry indicated a shift in coal flow from one outlet pipe to the other(s). However, it 
was not possible to quantify the amount of coal shift between pipes due to the symmetrical flow assumption.

As can be seen from Figure 19, the spherical object redistributed the highly concentrated particle region in the annulus region of the discharge turret. The difference in the particle concentration distribution in the outlet pipe for the cases with and without the spherical object can qualitatively be seen by comparing Figure 13 (Reference condition) and 19 (with spherical object). Figure 19 also shows that there is almost no coal flow in the outlet pipe due the spherical object inserted upstream of the outlet pipe while the coal flow is equally split between the outlet pipes for the reference case.
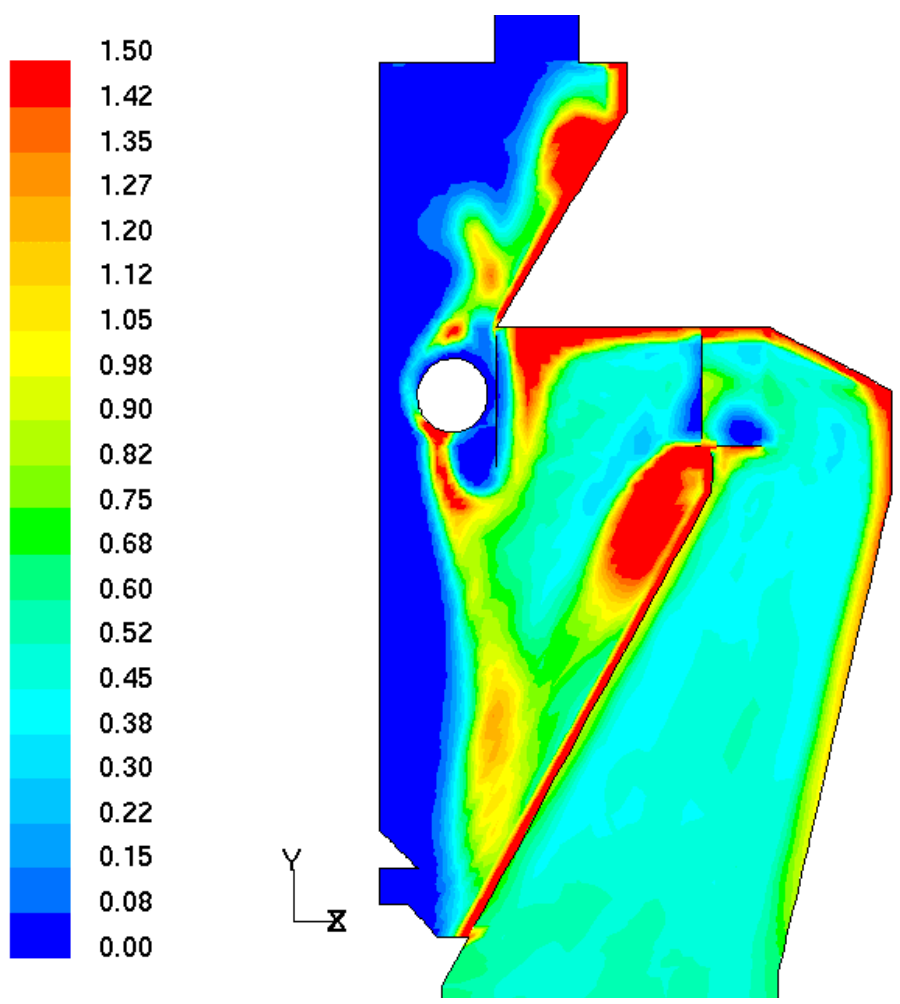

Figure 19: Particle Concentration Distribution in the Discharge Turret with a Spherical Object Inserted In

Figure 20 illustrates the computed primary air velocity vector in the pulverizer. It was found that the primary air flow distribution is strongly affected by the spherical flow control element at the inlet plane of the discharge turret. However, the spherical objects 
have negligible effect on the air flow distribution further downstream at inlet of the outlet pipes.
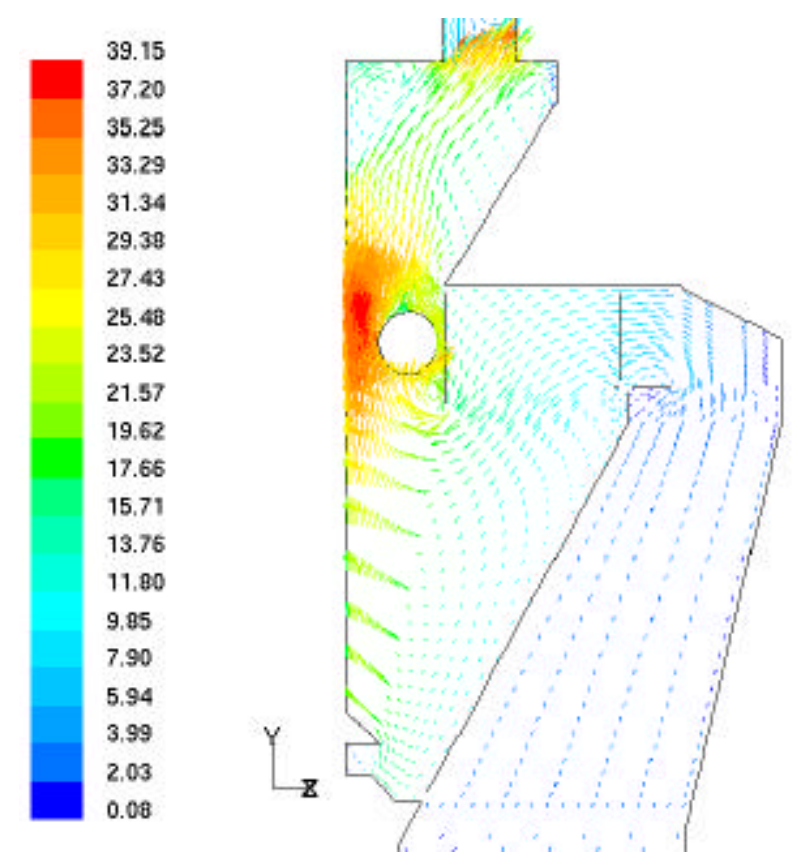

Figure 20: Primary Air Velocity Distribution in the Discharge Turret with a Spherical Object Inserted In

The results of the computer simulations with spherical objects indicate it should be possible to control outlet coal flow distribution with objects placed inside the pulverizer. In an effort to optimize flow controller design, research is continuing to find alternate shapes and locations for flow control elements. The most promising will then be tested in the laboratory.

\section{SUMMARY AND CONCLUSIONS}

This study focused on developing an on-line coal flow control technology for vertical spindle pulverizers in pulverized coal boilers. Numerical computations were performed by commercially available Computational Fluid Dynamics (CFD) software, Fluent. The CFD model was used to understand the complex three-dimensional flow structures in the upper half of the pulverizer and to help design the flow control mechanism. 
As a part of computational model development of the full-scale vertical spindle pulverizer, a literature review was carried out to find available experimental data for the geometries similar to the vertical spindle pulverizer. A Stairmand cyclone was found to be very similar to the vertical spindle pulverizer since both have strong swirling flows and particle separation within the geometry. The experimental data also helped to determine the CFD model parameters.

After model development and its verification, a full-scale pulverizer was modeled for a reference case with Fluent software, where there was no modification to the pulverizer. Examining the flow structures within the pulverizer guided us in designing the flow control elements and positioning them in the discharge turret. The flow domain for the case with a flow control element installed was computed.

The CFD results indicate that spherical objects could be used as flow control elements at the inlet plane of the discharge turret. CFD modeling for the vertical spindle pulverizer was a very helpful tool for understating the flow structures in the discharge turret and in evaluating proposed designs. The evaluation process is now being continued through additional computer simulations and through experiments using a laboratory scale pulverizer model as shown in Figure 21.

In the next phase of this investigation, the most promising of the candidate coal flow control designs will be evaluated experimentally in our laboratory by using an existing laboratory scale pulverizer model (Figure 21). 


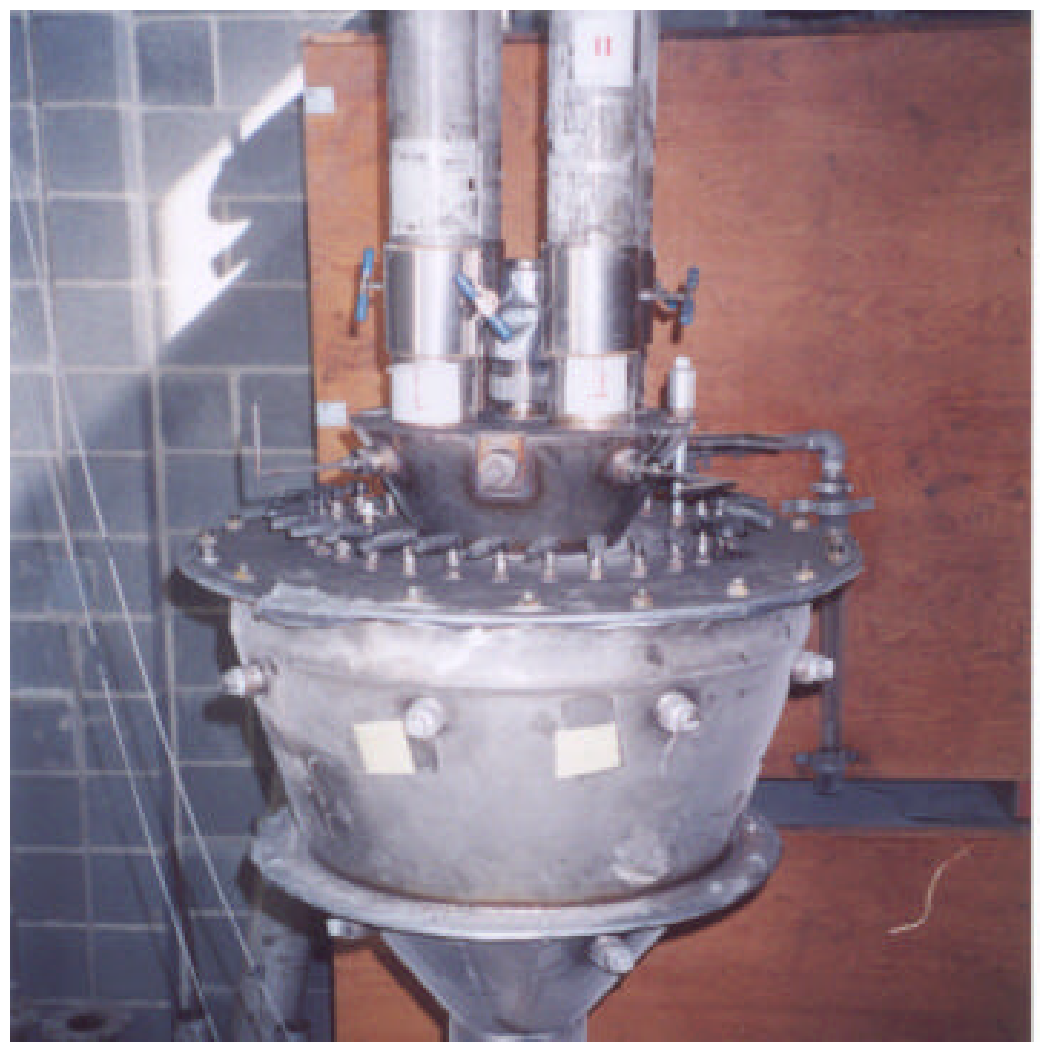

Figure 21: Pulverizer Model to be Tested in Laboratory

\section{REFERENCES}

1. Levy, E. K. and H. Bilirgen, "Balancing of Coal Flow Distribution to Pulverized Coal Burners," MEGA Conference, Washington D.C., June 2003.

2. Bilirgen, $\mathrm{H}$. and $\mathrm{C}$. Romero, "Coal Flow Balancing and Its Benefits at Logan Station," ERC Report No: 04-400-12-15, August 2004.

3. Bilirgen, H., "Mixing and Dispersion of Particle Ropes in Lean Phase Pneumatic Conveying," Lehigh University, Ph.D. Dissertation, DISS 2000 B595m, 2000.

4. Hoekstra, A. J., "Gas Flow Field and Collection Efficiency of Cyclone Separators," Delft University of Technology, Ph.D. Dissertation, ISBN 9090143341-3, 2000. 